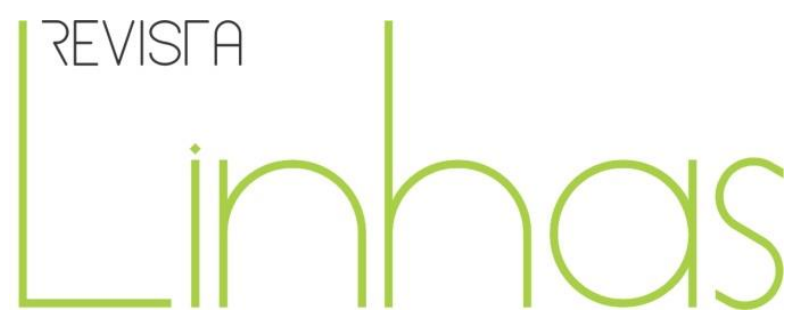

\title{
Imagen y práctica escolar en las memorias de oposición del franquismo: el caso de Baleares ${ }^{1}$
}

\begin{abstract}
Resumen
En los últimos tiempos los historiadores de la educación han fijado su atención en toda una serie de fuentes que nos acercan a las prácticas desarrolladas en la cotidianidad del aula. Entre este tipo de testimonios se encuentran las memorias pedagógicas que presentaban los maestros que optaban a ocupar plazas vacantes en el escalafón del magisterio dirección de escuelas graduadas, secciones de escuelas ubicadas en poblaciones de más de 10.000 habitantes, secciones y regencias de Escuelas anejas, etcétera-. Estos trabajos, conservados dentro de los expedientes de cada candidato, eran un requisito indispensable para participar en los concursos-oposición que celebró la administración pública. En esta ocasión hemos analizado aquellas memorias elaboradas por maestros que ejercieron en escuelas públicas de las Islas Baleares durante el franquismo (1939-1975). Se han localizado un total de 54 memorias que nos aportan datos sobre la práctica escolar. En ellas, además del discurso textual que presenta el maestro sobre su praxis, se encuentran otros vestigios que ayudan a reforzarlo -fotografías, cuadernos, libros, artículos publicados en la prensa pedagógica, etcétera-. En este artículo se analiza el papel de la imagen como elemento ilustrativo de aquellas prácticas que los maestros consideran más representativas de su actividad profesional.
\end{abstract}

Palabras clave: Memorias de oposición. Fotografía. Franquismo. Islas Baleares.
Gabriel Barceló-Bauzà

Universitat de les Illes Balears

(GEDHE-IRIE) - España

gabriel.barcelo@uib.cat

Sergi Moll-Bagur

Universitat de les Illes Balears

(GEDHE-IRIE) - España

sergimb_1@hotmail.com

Bernat Sureda-Garcia

Universitat de les Illes Balears (GEDHE-IRIE) - España bernat.sureda@uib.es

\section{Para citar este artigo:}

BARCELÓ-BAUZÀ, Gabriel; MOLL-BAGUR, Sergi; SUREDA-GARCIA, Bernat. Imagen y práctica escolar en las memorias de oposición del franquismo: el caso de Baleares. Revista Linhas. Florianópolis, v. 20, n. 44, p. 2841, set./dez. 2019.

\section{DOI: $10.5965 / 1984723820442019028$}

http://dx.doi.org/10.5965/1984723820442019028

\footnotetext{
${ }^{1}$ Artículo realizado en el marco del proyecto Cultura y prácticas escolares en el siglo XX. EDU2017-82485-P, financiado por el Ministerio de Ciencia, Innovación y Universidades (MCIU), la Agencia Estatal de Investigación (AEI) y el Fondo Europeo de Desarrollo Regional (FEDER, UE). Esta investigación se presentó en forma de comunicación en las VIII Jornadas Científicas de la Sociedad Española para el Estudio del Patrimonio Histórico-Educativo (SEPHE) - I Congresso Nazionale della Società Italiana per lo Studio del Patrimonio Storico-Educativo (SIPSE) y se publicó en el libro de actas La Práctica Educativa. Historia, Memoria y Patrimonio (GONZÁLEZ, Sara, MEDA, Juri, MOTILLA, Xavier y POMANTE, Luigiaurelio (Eds.). Salamanca: FahrenHouse, 2018, p. 671-682).
} 


\section{Image and school practice in pedagogical reports under the Franco regime: a look at the Balearic Islands}

\begin{abstract}
In recent times, historians of education have focused their attention on a whole series of sources that bring us closer to the practices developed in the everyday life of the classroom. Among these types of testimonies are the pedagogical reports presented by the teachers who opted to fill primary school vacancies - primary school directions, grades of schools located in towns with more than 10,000 inhabitants, grades and school directions that depends of the teachers training schools, etcetera -. These works, conserved within the dossiers of each candidate, were an indispensable requirement to participate in the competitive examinations held by the public administration. On this occasion, we have analysed those pedagogical reports drawn up by teachers who worked in state schools of the Balearic Islands during the Franco regime (1939-1975). A total of 54 pedagogical reports have been found that provide us with data on school practice. In them, in addition to the textual discourse that the teachers present about his praxis, there are other vestiges that help to reinforce it -photographs, notebooks, books, articles published in the pedagogical press, etcetera-. This article analyses the role of the image as an illustrative element of those practices that teachers consider most representative of their professional activity.
\end{abstract}

Keywords: Pedagogical reports. Photography. Franco regime. Balearic Islands.

\section{Imagem e prática escolar nos memoriais de concurso do franquismo: o caso de Baleares}

\begin{abstract}
Resumo
Nos últimos tempos, os historiadores da educação têm voltado a sua atenção para toda uma série de fontes que nos aproximam das práticas desenvolvidas no cotidiano da sala de aula. Dentro desse tipo de testemunhos se encontram os memoriais pedagógicos que apresentavam os professores que optavam por ocupar vagas na hierarquia do magistério direção de escolas graduadas, seções de escolas localizadas em povoados de mais de 10.000 habitantes, seções e regências de escolas anuais, etc. Estes trabalhos, conservados dentro dos memoriais de cada candidato, eram um requisito indispensável para participar dos concursos que a administração pública abriu. Nesta ocasião, analisamos os memoriais elaborados por professores que trabalharam nas escolas públicas das Ilhas Baleares durante o franquismo (1939-1975). Localizou-se um total de 54 memoriais, que nos trazem dados sobre a sua prática escolar. Neles, além do discurso textual que o professor apresenta sobre a sua prática, encontram-se outros vestígios que ajudam a reforçá-lo - fotografias, cadernos, livros, artigos publicados na imprensa pedagógica, etc. Neste artigo, analisa-se o papel da imagem como elemento ilustrativo das práticas que os professores consideram mais representativas da sua atividade profissional.
\end{abstract}

Palavras-chave: Memoriais de concurso. Fotografia. Franquismo. Ilhas Baleares. 


\section{Introducción}

El estudio de la práctica escolar puede considerarse una de las tendencias más en boga de la investigación histórico-educativa actual. No obstante, el análisis de esta práctica, o lo que algunos estudiosos denominan cultura empírica de la escuela (ESCOLANO, 2000), requiere explorar nuevas fuentes que nos ayuden a observar su evolución en el pasado. En otras ocasiones ya hemos recurrido a estos testimonios. Ejemplo de ello son las memorias de prácticas de los alumnos de magisterio utilizadas para aproximarnos a las prácticas escolares de las escuelas de Baleares durante el franquismo (BARCELÓ, COMAS y SUREDA, 2016; BARCELÓ, MOLL y SUREDA, 2017).

En la investigación que a continuación presentamos nos centramos en una documentación localizada en el Archivo General de la Administración (A.G.A.). Se trata de los expedientes de oposición para la provisión de vacantes en enseñanza primaria del período franquista (1939-1975), sin duda, unos fondos documentales con un gran potencial como fuentes histórico-educativas. Al tratarse de concursos-oposición dirigidos a maestros en activo, la mayoría de éstos cuentan, entre otros documentos, con memorias pedagógicas en las que los concursantes reflejan, con más o menos detalle, cómo ha sido su práctica desde su ingreso en el escalafón del magisterio (DEL POZO, 2013; BARCELÓ, COMAS y DEL POZO, 2018; MENGUIANO, 2019). Además del discurso narrativo, las memorias también contienen otros testimonios que ilustran la praxis desarrollada por cada opositor: libros, cuadernos, fotografías, materiales didácticos, artículos publicados en la prensa pedagógica, etcétera. En este artículo se realiza una primera aproximación al discurso iconográfico de las fotografías que los maestros adjuntan en sus relatos. En ellas vemos el papel que ejerce la imagen como instrumento para la reconstrucción y publicitación de algunas de las prácticas escolares que se llevaron a cabo durante el franquismo en escuelas públicas de Baleares. Cabe añadir, que el estudio de las imágenes como fuente para el estudio de la historia de la educación ha sido uno de los temas de investigación al que el Grup d'Estudis d'Història de l'Educació del Institut de Recerca i Innovació Educativa (IRIE) - Universitat de les Illes Balears (UIB) se ha dedicado en los últimos diez años (COMAS y SUREDA, 2018). 


\section{Las memorias de oposición como fuente para el estudio de la práctica escolar}

El estudio de la práctica escolar desde una perspectiva histórica requiere ser abordada desde diferentes perspectivas y mediante el análisis de fuentes muy diversas, todas ellas necesarias y complementarias para un conocimiento de la temática testimonios orales, materiales de enseñanza, memorias pedagógicas, libros y cuadernos escolares, fotografías, exámenes, etcétera -. En esta ocasión hemos optado por centrarnos en las memorias pedagógicas que redactaron entre 1939 y 1975 aquellos maestros que optaban a plazas vacantes en Baleares. Para su localización se ha procedido a la revisión de los inventarios de la documentación correspondiente a los diferentes concursos-oposición que se celebraron durante la Dictadura. Ubicados dentro de los fondos documentales de la Dirección General de Enseñanza Primaria que alberga la sección de Educación y Ciencia del A.G.A., se ha constatado que del período franquista existen, entre cajas y legajos, más de un millar de unidades. En ellas, además de las oposiciones para proveer plazas vacantes del magisterio, se custodia la documentación generada por otras convocatorias relacionadas con la enseñanza primaria -ingreso en el escalafón del magisterio, acceso y promoción en el cuerpo de inspectores de enseñanza primaria, oposiciones a cátedras de Escuelas Normales, etcétera-.

Centrándonos en los concursos para provisión de plazas vacantes se han encontrado convocatorias de diversa índole -secciones de escuelas anejas a las Escuelas del Magisterio, direcciones de escuelas graduadas, secciones en escuelas ubicadas en poblaciones de más de 10.000 habitantes, etcétera-. Respecto a la documentación generada en cada una de ellas debemos destacar las actas de los tribunales evaluadores, los exámenes, las calificaciones, así como los expedientes de cada uno de los maestros participantes. Éstos últimos se componen de diferentes documentos como la hoja de servicios, el recibo del pago efectuado para tener derecho a examen, la instancia en la que se indicaban las plazas vacantes a las que se quería optar en caso de aprobar la oposición, así como la memoria pedagógica en la que se refleja la labor desarrollada por

el maestro en la escuela primaria. Otras pruebas documentales que también figuran en los expedientes de los docentes son aquellas en las que se acredita que la conducta 
profesional y moral del opositor es intachable. Normalmente eran informes emitidos por los inspectores de enseñanza primaria, los alcaldes, los párrocos, o bien, por personas ligadas a los organismos oficiales del régimen franquista como: Sección Femenina, Frente de Juventudes, etcétera. En dichos documentos siempre se exaltaban los méritos del maestro candidato en relación a la rebelión militar contra la República a la que llaman «Glorioso Movimiento Nacional».

Respecto a la crítica de estas fuentes, debemos señalar en primer lugar que quienes se presentaban a estos concursos representaban algo así como las élites del magisterio, tanto por su formación como por su experiencia. Aun teniendo en cuenta qué en estas memorias, por su finalidad, se presenta una visión idealizada de la práctica escolar y las actuaciones que se habían realizado y, que la práctica profesional que describen no es necesariamente representativa de lo que hacían la mayoría de maestros, consideramos útil la información que nos ofrecen, pues permiten una lectura de lo que fue la práctica desarrollada por los maestros durante el franquismo.

\section{Imagen y práctica docente en las memorias de oposición del franquismo. Una aproximación a través del caso de Baleares}

Para esta ocasión, hemos considerado interesante analizar las fotografías que adjuntan en las memorias pedagógicas aquellos maestros que opositaron durante el franquismo para proveer plazas vacantes en la provincia de Baleares. En general los testimonios fotográficos del pasado educativo tienden a presentar una realidad idealizada, a mostrar aquellas situaciones o actividades que se consideran modélicas o relevantes y a ocultar otras que se consideran inadecuadas (COMAS, 2010). En este caso también los testimonios gráficos, además de ser un instrumento de apoyo al discurso textual, nos muestran aquellas prácticas que los opositores consideran dignas de ser publicitadas. Igualmente, otros aspectos, que por otros testimonios como los orales, sabemos que estaban presentes en la práctica diaria, como eran los castigos corporales, no aparecen en las fotografías lo que nos hace reflexionar sobre los silencios que éstas, como otras fuentes, presentan. 
Pasando al fondo sobre el que hemos trabajado, cabe mencionar que, de las 54 memorias de oposición halladas, un total de 13 conservan fotografías -8 fueron realizadas por maestras y 5 por maestros-. Si bien la gran mayoría pertenecen al período franquista, también se adjuntan algunas anteriores al alzamiento militar de 1936 -pese a ello, en el presente texto no entraremos en el análisis de aquellas que se realizaron antes de la Guerra Civil-. Respecto al total de fotografías encontradas, éstas ascienden a 207.

Centrándonos en las imágenes halladas en las memorias, debemos señalar que nos encontramos ante unos excelentes testimonios que nos permiten aproximarnos a algunas de las prácticas que se llevaron a cabo en escuelas públicas de Baleares durante el franquismo. A través de los testimonios visuales, además de ver algunos de los elementos más característicos de la cultura escolar del momento, observamos el papel que ejerce la fotografía en la publicitación de aquellas prácticas que los maestros consideran más representativas de su actividad profesional. Realizadas estas apreciaciones, pasamos a describirlas.

El primer punto que queremos señalar son las fotografías que hacen referencia a la metodología de enseñanza aplicada. En este caso, las imágenes halladas nos demuestran cierta ambivalencia en las estrategias de enseñanza-aprendizaje. Si bien algunos maestros que opositaron durante los años cuarenta y principios de los cincuenta adjuntan fotografías de sus alumnos realizando actividades ligadas a la enseñanza activa e intuitiva (Fotografías 1 y 2), vemos como a medida que nos adentramos en los años de la Dictadura las imágenes ilustran un tipo de enseñanza más memorística y dirigida (Fotografías 3 y 4). Las dos primeras fotografías son de los opositores Miguel Deyá Palerm (JAUME, 2001) y Margarita Bordoy Sansó (CÀNAVES, SERRA y SERRA, 1997), maestros formados con anterioridad al inicio de la Dictadura y con influencias de los movimientos educativos renovadores de las primeras décadas del siglo XX. En el caso de Miguel Deyá, que aparece en la fotografía con sus alumnos junto a una imprenta, fue un destacado freinetista. En el caso de Margarita Bordoy se muestran los trabajos manuales una actividad de amplia tradición en la pedagogía renovadora. 


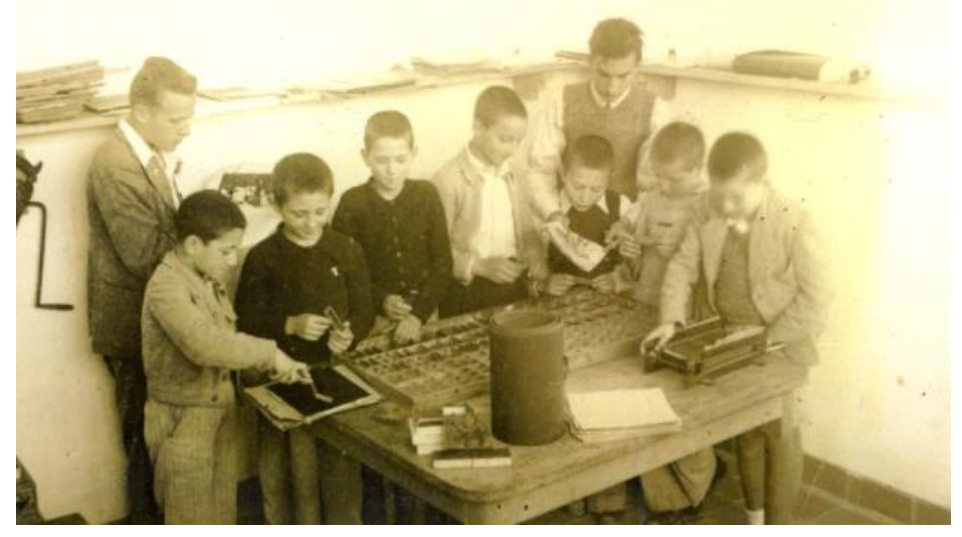

Fotografía 1. Alumnos de la escuela de Son Espanyolet (Palma) junto a la imprenta escolar (Deyá, 1941).

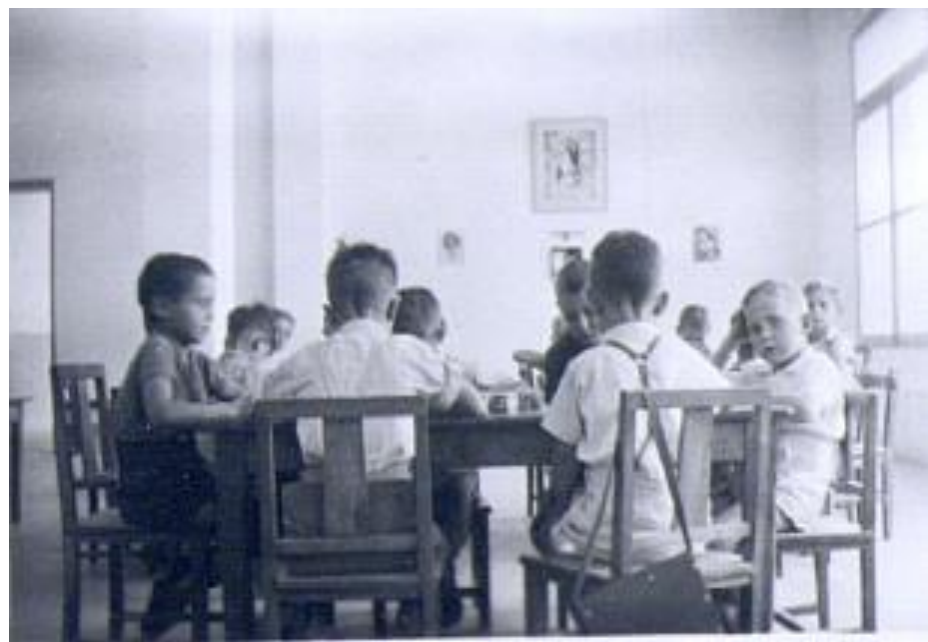

Fotografía 2. Alumnos de la escuela de Santa Isabel (Palma) en clase de trabajos manuales (Bordoy, 1950).

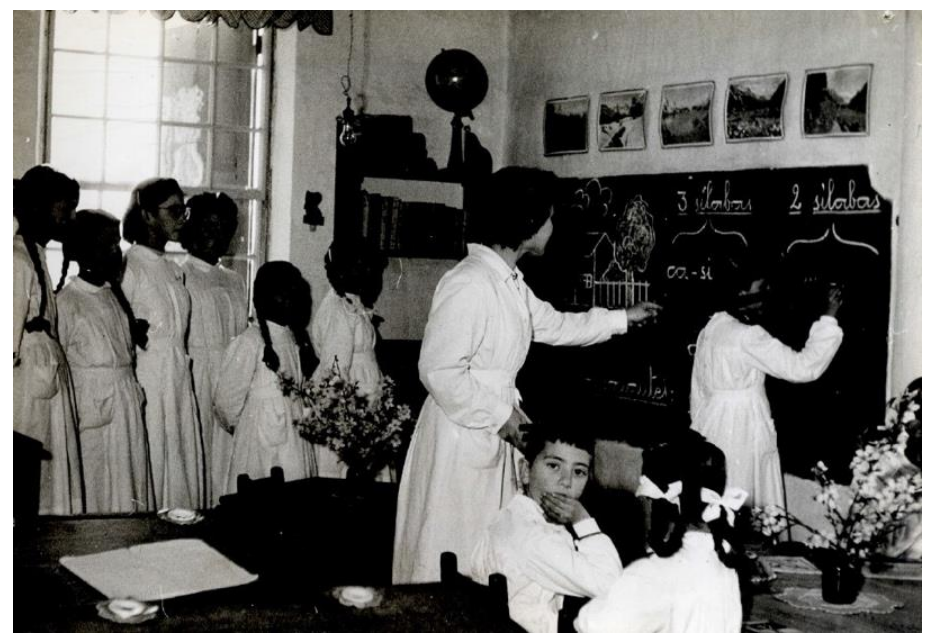

Fotografía 3. Alumnas de la escuela de Sant Climent (Mahón) realizando ejercicios de escritura junto a su maestra (Seguí, 1959). 


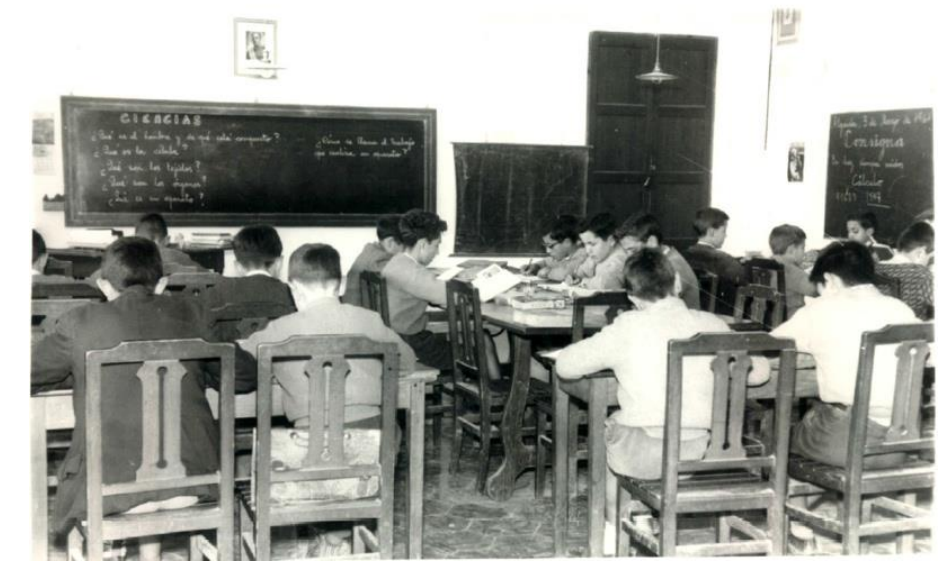

Fotografía 4. Alumnos de la escuela graduada de niños de Algaida realizando ejercicios de lectura silenciosa (Guillem, 1960).

Otro aspecto que ilustran las fotografías son aquellas actividades que se realizaban fuera del aula -excursiones, competiciones deportivas, etcétera-. Las salidas a la playa, las visitas a monumentos (Fotografía 5), así como las secuencias de partidos de futbol, baloncesto, o incluso balonmano (Fotografía 6), son otras de las prácticas que más se publicitan en los testimonios visuales.

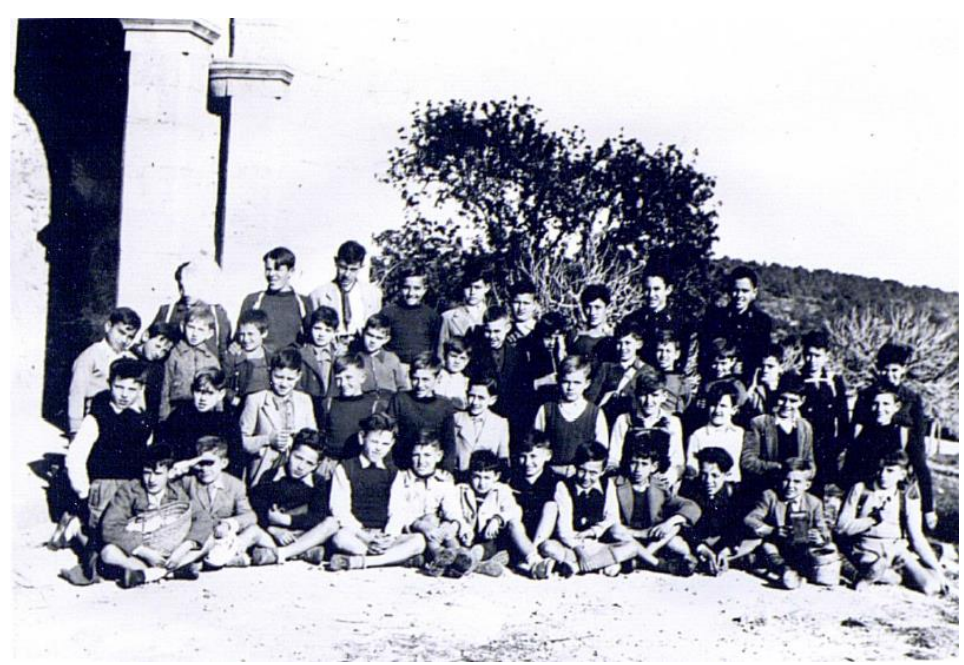

Fotografía 5. Alumnos de la escuela de Pere Garau (Palma) en el castillo de Alaró (Aulí, 1966). 


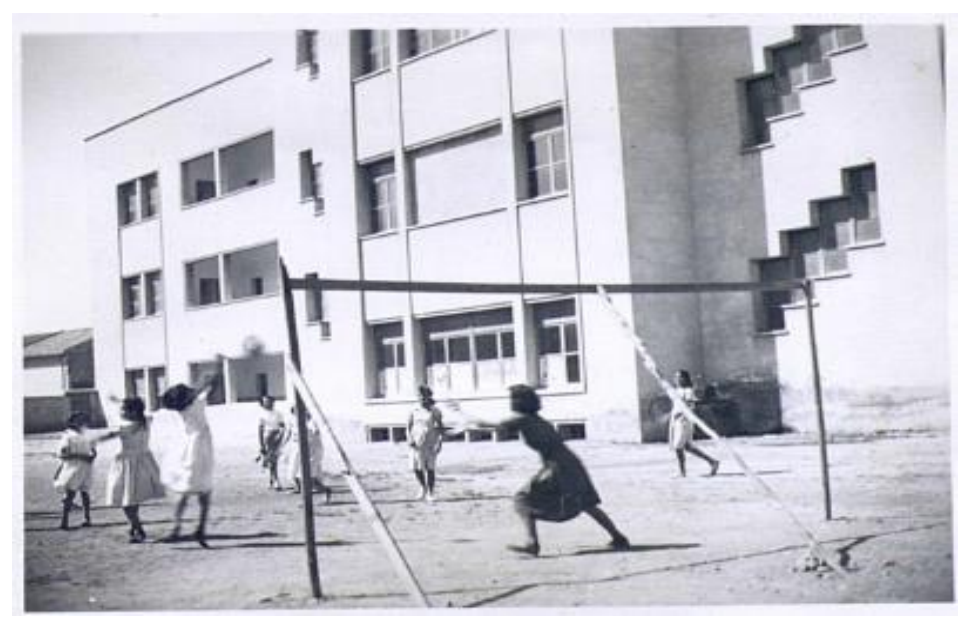

Fotografía 6. Alumnas de la escuela de Santa Isabel (Palma) jugando a balonmano (Nolla, 1950).

Aparte de la metodología de enseñanza y demás actividades realizadas fuera del aula, las memorias de los docentes también nos enseñan los edificios y espacios donde han Ilevado a cabo sus prácticas. En ellas, además de ilustrarnos las características arquitectónicas de algunos edificios (Fotografía 7), también podemos ver la ornamentación, simbología, mobiliario o material didáctico que formaba parte del aula (Fotografía 8).



Fotografía 7. Fachada del Grupo Escolar José Antonio (Ibiza) (Santandreu, 1950). 


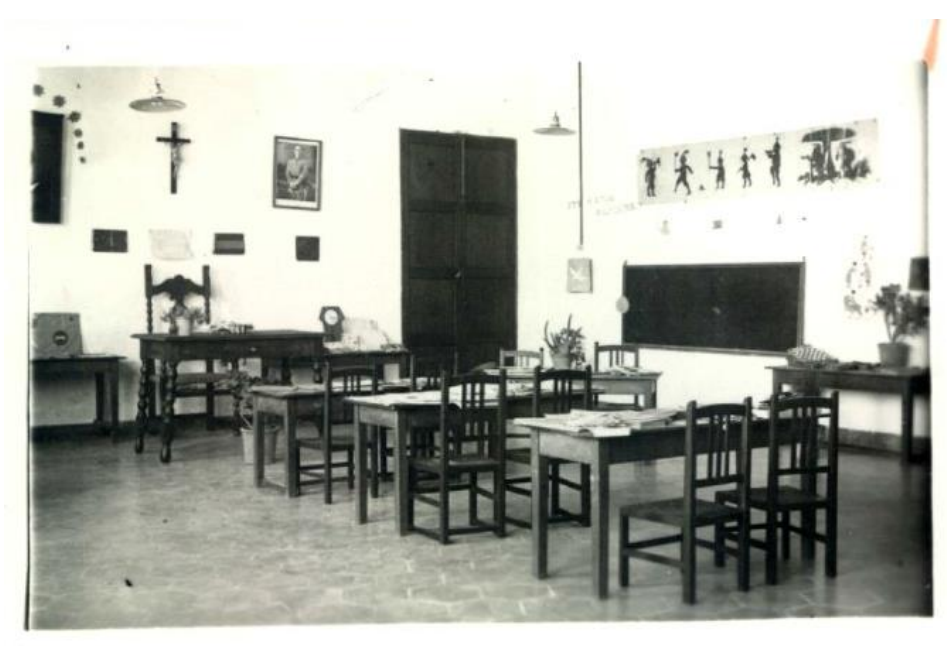

Fotografía 8. Aula de la sección de párvulos de la escuela graduada de Algaida (Marroig, 1948).

Otro aspecto que se quiere reflejar a nivel visual es la sintonía entre la actividad docente y la ideología del Régimen. Si bien en algunos casos, como ya se ha indicado, tanto a nivel narrativo como visual, observamos la pervivencia de ciertas prácticas relacionadas con los movimientos de renovación pedagógica -excursiones, trabajos manuales, etcétera-, las imágenes que adjuntan los maestros en sus memorias también dejan constancia de su fidelidad ideológica con el nacionalcatolicismo imperante. La celebración del Mes de María o las exposiciones escolares de carácter religioso o patriótico (Fotografía 9) son otras de las prácticas que ilustran los maestros a través de las fotografías.

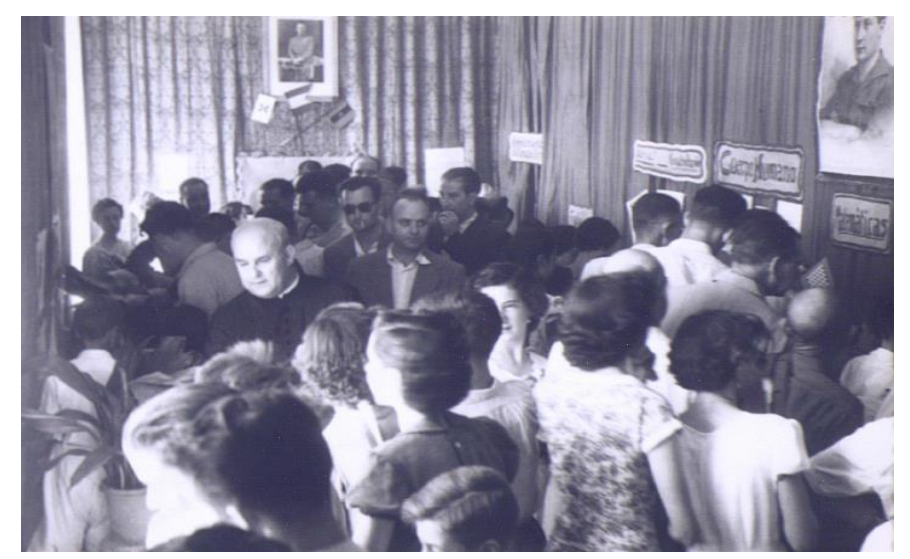

Fotografía 9. Exposición de fin de curso en la escuela graduada de Alaró (Rotger, 1966). 
En los testimonios analizados, además de los aspectos mencionados hasta el momento, también se incluyen imágenes de algunas prácticas que empezaron a implementarse durante los últimos años del franquismo. Este es el caso de la educación vial, un contenido curricular que se establece como obligatorio en la escuela primaria a partir de la Orden de 29 de abril de 1961 (BARCELÓ y GELABERT, 2019). En Baleares, Campos fue el primer municipio con un Parque Infantil de Tráfico con carácter permanente (Fotografía 10). Éste, inaugurado el 19 de mayo de 1963, se ubicó junto a la escuela nacional de niños de la citada localidad.

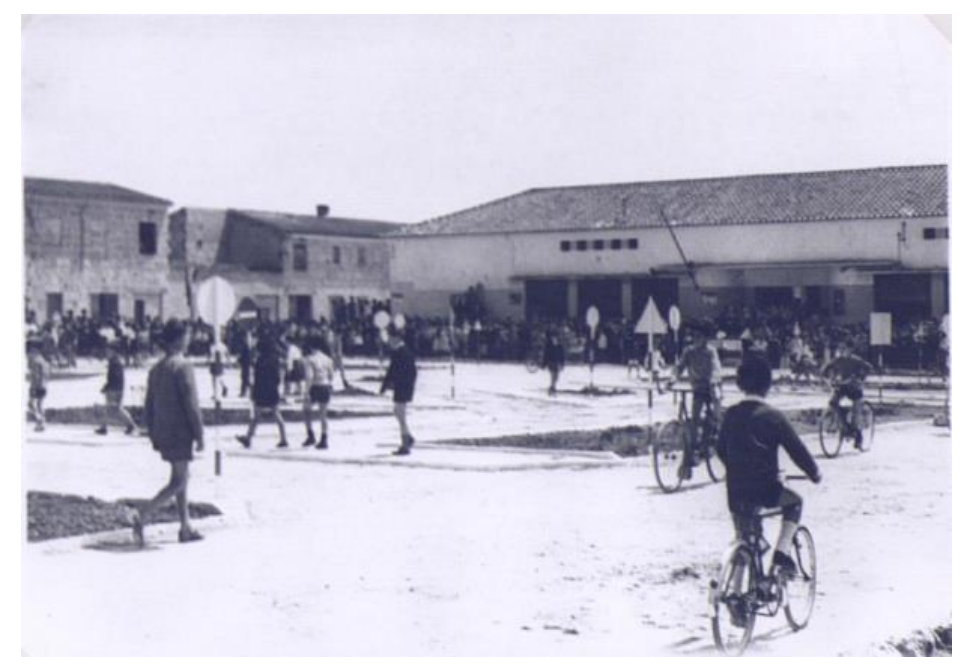

Fotografía 10. Alumnos de la escuela graduada de Campos realizan una demostración el día de la inauguración del Parque Infantil de Tráfico (Ponseti, 1966).

En última instancia, queremos mencionar que si bien en este texto se ha presentado una pequeña muestra de las fotografías que acompañan al discurso textual de las memorias de oposición, consideramos que con los diferentes ejemplos se ha podido aproximar al lector a una parte de las prácticas que publicitan los maestros. Consideramos que de cara al futuro sería interesante que este trabajo se pudiera complementar con investigaciones de otras regiones de la geografía española. Creemos que así podríamos analizar con mayor rigor qué prácticas tienen mayor presencia, a nivel visual, en las memorias del período franquista. En última instancia queremos señalar que este tipo de testimonios, como es el caso de las fotografías, también nos sirven para 
entrever algunos de los cambios y continuidades que caracterizaron la cultura escolar franquista.

\section{Conclusiones}

A continuación, presentamos una serie de reflexiones finales. En primer lugar, es preciso destacar que a través de esta investigación hemos querido poner en valor las memorias de oposición, una de las fuentes que nos permiten acercarnos a la cotidianidad de los centros escolares, conociendo así algunas de las prácticas escolares que se llevaron a cabo durante los años de la dictadura franquista.

El segundo aspecto a remarcar es la importancia que tienen este tipo de testimonios cuando nuestro objetivo es el de analizar la construcción histórica de la escuela. $Y$ es que para conocer la evolución de la práctica escolar es necesario adentrarnos en aquellas fuentes -fotografías, libros, cuadernos, materiales didácticos, memorias pedagógicas, etcétera- que nos permiten asomarnos a algunas de las actividades que se llevaron a cabo en el día a día.

En tercer lugar, se ha puesto de manifiesto como los testimonios visuales que adjuntan los maestros en las memorias sirven de elemento para la publicitación de aquellas prácticas que consideran más representativas de su actividad profesional. Asimismo, también se constata el papel que ejerce la fotografía en la representación de los modelos pedagógicos que se consideran ideales.

Por último, hemos querido poner al alcance de la comunidad científica las fotografías que se adjuntan en las memorias de oposición del período franquista referentes a Baleares. Hecho que nos ha permitido conocer algunas de las prácticas que se desarrollaron en este territorio en un momento de cambio radical de la política en general y de la educativa en particular. 


\section{Referencias}

BARCELÓ, Gabriel; COMAS, Francisca; SUREDA, Bernat. Abriendo la caja negra: la escuela pública española de postguerra. Revista de Educación, n. 371, p. 61-82, 2016.

BARCELÓ, Gabriel; MOLL, Sergi; SUREDA, Bernat. La escuela privada religiosa en Mallorca durante la postguerra. Cultura y práctica escolar. History of Education \& Children's Literature, v. 12, n. 2, p. 191-212, 2017.

BARCELÓ, Gabriel; COMAS, Francisca; DEL POZO, María del Mar. La práctica escolar durante los primeros años del franquismo. História da Educação, v. 22, n. 54, p. 334-357, jan / abr 2018.

BARCELÓ, Gabriel; GELABERT, Llorenç. Educación vial durante el franquismo. Memoria de los primeros parques infantiles de tráfico en Mallorca (1962-1975). Historia y Memoria de la Educación, n. 10, p. 345-379, 2019.

CÀNAVES, Maria; SERRA, Joana; SERRA, Maria Antònia. Francesc Rosselló i Gil i Margalida Bordoy i Sansó. Palma: Servei de Publicacions de la Universitat de les Illes Balears [Col·lecció Els nostres educadors, núm. 5], 1997.

COMAS, Francisca. Fotografia i història de l'educació. Educació i Història: revista d'història de l'educació, n. 15, p. 11-17, ene / jun 2010.

COMAS, Francisca; SUREDA, Bernat. Fotografia i història de l'educació. Deu anys de recerca en el Grup d'Estudis d'Història de l'Educació de la UIB. In: Institut de Recerca i Innovació Educativa (IRIE). Informe de recerca (número 16). Palma: IRIE, 2018. http://ibdigital.uib.es/greenstone/collect/IRIEInformesRecercaVolums/index/assoc/16_201 8_dir/16_2018_fotografia_historia_educacio.pdf

ESCOLANO, Agustín. Las culturas escolares del siglo XX. Encuentros y desencuentros. Revista de Educación, número extraordinario, p. 201-218, 2000.

JAUME, Miquel. Freinet a Mallorca. Miquel Deyà Palerm i l'escola de Consell (1930-1940). Palma: Lleonard Muntaner Editor, 2001.

MENGUIANO, Carlos. Los expedientes-oposición a direcciones de escuelas graduadas de 1932 como fuente histórico-educativa. Un estudio de caso: el expediente-oposición de María Sánchez Arbós. Historia y Memoria de la Educación, n. 10, p. 309-344, 2019.

DEL POZO, María del Mar. Justa Freire o la pasión de educar. Biografía de una maestra atrapada en la historia de España (1896-1965). Barcelona: Editorial Octaedro, 2013. 


\section{Referencias archivísticas}

Relación completa de las memorias que contienen fotografías de escuelas de Baleares entre 1939 y 1975. Archivo General de la Administración (A.G.A.). Sección Educación y Ciencia. Expedientes de provisión de plazas vacantes en el escalafón del magisterio nacional (Dirección General de Enseñanza Primaria).

AMENGUAL FONDEVILA, Juana Ana. 1959. Memoria pedagógica. Legajo 17.850.

AULí BOSCH, Pedro. 1966. Memoria pedagógica. Caja 32/01457.

BORDOY SANSÓ, Margarita. 1950. Memoria pedagógica. Legajo 17.107.

CASTRO AMO, Pilar. 1951. Memoria pedagógica. Legajo 17.054.

DEYÁ PALERM, Miguel. 1941. Memoria pedagógica. Caja 31/3127.

GUILLEM ARBONA, Antonio. 1960. Memoria pedagógica. Legajo 17.694.

MARROIG MIGUEL, Catalina. 1948. Memoria pedagógica. Caja 31/5326.

NOLLA OLIVER, Catalina. 1950. Memoria pedagógica. Legajo 17.107.

PONSETI OLIVES, Pedro. 1966. Memoria pedagógica. Caja 32/01461.

ROTGER PIZÁ, Andrés. 1966. Memoria pedagógica. Caja 32/01462.

SANTANDREU BUÑOLA, María. (1950). Memoria pedagógica. Legajo 17.107.

SEGUÍ MERCADAL, Catalina. 1959. Memoria pedagógica. Legajo 17.850.

SEGURA CORTÉS, Isabel. 1951. Memoria pedagógica. Legajo 17.054.

Recebido em: 03/05/2019

Aprovado em: 11/06/2019

Universidade do Estado de Santa Catarina - UDESC

Programa de Pós-Graduação em Educação - PPGE

Revista Linhas

Volume 20 - Número 44 - Ano 2019

revistalinhas@gmail.com 